\title{
ANÁLISE DA SUBSUPERFÍCIE COM SONDAGEM ELÉTRICA VERTICAL (SEV) NOS MUNICÍPIOS DE CAPANEMA E PRIMAVERA, NORDESTE DO ESTADO DO PARÁ
}

\author{
SUBSUPERFACE ANALYSIS WITH VERTICAL ELECTRICAL SOUNDING (SEV) IN THE \\ MUNICIPALITIES OF CAPANEMA AND PRIMAVERA, NORTHEAST OF THE STATE OF PARÁ
} \author{
Joelson Lima SOARES ${ }^{4}$ \\ ${ }^{1}$ Graduação em Geofísica, Instituto de Geociências, Universidade Federal do Pará, Belém, Pará, Brasil. \\ Email: danilosilva.geof@gmail.com \\ Email: danielepantojamonteiro@gmail.com \\ ${ }^{3}$ Departamento de Geofísica, Instituto de Geociências, Universidade Federal do Pará, Belém, Pará, Brasil. \\ Email: hba.ufpa@gmail.com

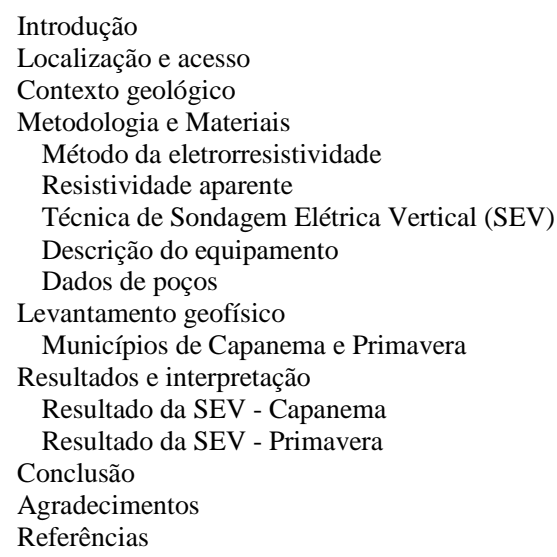

Danilo da SILVA ${ }^{1}$, Daniele Pantoja MONTEIRO ${ }^{2}$, Hugo Richard Bertete AGUIRRE ${ }^{3}$,

${ }^{2}$ Programa de Pós-graduação em Geofísica, Instituto de Geociências, Universidade Federal do Pará, Belém, Pará, Brasil.

${ }^{4}$ Departamento de Geologia, Instituto de Geociências, Universidade Federal do Pará, Belém, Pará, Brasil. Email: jlsoares@ufpa.br

RESUMO - Estudos geológicos e geofísicos baseados na técnica de investigação Sondagem Elétrica Vertical (SEV) foram utilizados na identificação de litofácies de origem tectônica dos depósitos neógenos carbonáticos e siliciclásticos, correspondentes as Formações Pirabas e Barreiras, e sedimentos da unidade Pós-Barreiras, que constituem o preenchimento da Plataforma Bragantina, nos municípios de Capanema e Primavera, região continental do nordeste do estado do Pará. Os dados de resistividade aparente das sondagens elétricas foram processadas utilizando o programa IPI2win, que é projetado para realizar inversões 1D automáticas, correlacionando-as sempre que possível com os perfis litológicos de poços, disponíveis na plataforma online do Sistema de Informação de Águas Subterrâneas (SIAGAS), com o intuito de ajustar os valores de espessuras das camadas (fornecidas pelos perfis ) com a solução do modelo geoelétrico e estimando-se as resistividades de cada camada de acordo com a composição mineralógica descrita nos poços. Os resultados das sondagens elétricas realizadas neste trabalho mostraram-se satisfatórias, pois permitiram diferenciar o possível contato entre a Formação Pirabas com o embasamento cristalino a uma profundidade em torno de 50 metros no município de Capanema, devido o forte contraste de resistividade, no município de Primavera diferenciou as Formações Pirabas e Barreiras, em torno de 9 metros de profundidade.

Palavras-chave: Sondagem Elétrica Vertical (SEV). Neógeno. Nordeste do Estado do Pará.

ABSTRACT - Geological and geophysical studies based on the Vertical Electrical Sounding (VES) research technique were used in the identification of tectonic lithofacies of the carbonates and siliciclastic Neogene deposits, corresponding to the Pirabas and Barreiras Formations, and sediments of the Post-Barreiras unit, which constitute the Bragantina Platform, in the municipality of Capanema and Primavera, continental region of the northeast of the state of Pará. The apparent resistivity data of the electrical soundings were processed using the IPI2win program, which is designed to perform automatic 1D inversions, correlating them whenever possible with the lithological profiles of wells, available in the online platform of the Groundwater Information System (SIAGAS ), with the purpose of adjusting the thickness values of the layers (provided by the profiles) with the solution of the initial geoelectric model and estimating the resistivities of each layer according to the mineralogical composition described in the wells. The results of the electrical soundings carried out in this work were satisfactory, since they allowed to differentiate the possible contact between the Pirabas Formation with the crystalline basement at a depth of around 50 meters in the municipality of Capanema, due to the strong resistivity contrast, and in the Pirabas and Barreiras Formations, around 9 meters deep.

Keywords: Vertical Electrical Sounding (SEV). Neogene. Northeast of Pará State.

\section{INTRODUÇÃO}

A sucessão miocênica do estado do Pará depositou-se sob condições de forte controle tectônico, com o desenvolvimento de vales incisos que se encaixam ao longo de zonas de falhas (Rossetti \& Góes, 2004). As estruturas que controlaram a deposição da Formação Pirabas e do grupo Barreiras são falhas normais NW-SE e inclinadas para NE, e falhas transcorrentes NE-SW que funcionaram como zonas de transferência. Apesar da grande 
distribuição, estes depósitos ainda são insuficientemente documentados em pesquisas geofísicas, sendo alvo, nas últimas décadas, de estudos como a utilização do Radar de Penetração no Solo (GPR-Ground Penetrating Radar), Silva (2015), além de trabalhos aplicando a gravimetria Vieira (2015) para promover um aprofundamento no conhecimento científico da região.

Neste trabalho foi aplicado um dos métodos geoelétricos existente, o método da eletrorresistividade, que se baseia na determinação da propriedade física (resistividade elétrica) que caracterizam os diferentes tipos de materiais encontrados no ambiente geológico, e nos contrastes que estas propriedades podem apresentar. A técnica de investigação aplicada no desenvolvimento do método foi à sondagem elétrica vertical (SEV), esta investiga verticalmente (ponto a ponto) o parâmetro físico (resistividade elétrica aparente) com a profundidade efetuada na superfície do terreno.

A investigação por meio de sondagem elétrica vertical que é uma técnica complementar para caracterizar os depósitos carbonáticos e siliciclásticos das formações Pirabas e Barreiras e tentar localizar a profundidade do embasamento nos municípios de Capanema e Primavera.

Com o método foram realizadas coletas de corrente e potencial e posteriormente calculando a resistividade aparente usando a técnica sondagem elétrica vertical, com perfis entorno de $500 \mathrm{~m}$ na horizontal tanto em Capanema como em Primavera, em ambos locais foi aplicado com o Arranjo Wenner.

O propósito deste trabalho foi identificar os limites entre as principais formações rochosas da área estudada, as Formações Barreiras e Pirabas e o limite entre a Formação Pirabas e o embasamento cristalino nos municípios de Capanema e Primavera, região continental do nordeste do estado do Pará.

\section{LOCALIZAÇÃO E ACESSO}

As áreas de estudo estão localizadas na região continental do nordeste do estado do Pará, nos municípios de Capanema e Primavera.

O município de Capanema está localizado a uma latitude $01^{\circ} 11^{\prime} 45^{\prime \prime}$ sul e a uma longitude 47 $10^{\prime} 51^{\prime \prime}$ oeste e dista cerca de $163 \mathrm{~km}$. Sua população estimada em 2016 era de 66.759 habitantes, o acesso é feito via BR-316 (Belém -
Brasília).

A outra área de estudo é o município de Primavera está localizado a uma latitude $00^{\circ} 56^{\prime}$ $25^{\prime \prime}$ sul e a uma longitude $47^{\circ} 06^{\prime} 59^{\prime \prime}$ oeste, e dista cerca de $205 \mathrm{Km}$ da Capital Belém e o acesso é feito via BR-316 (Belém - Brasília) e a PA-124. A localização das cidades mencionadas é mostrada na figura 1 .

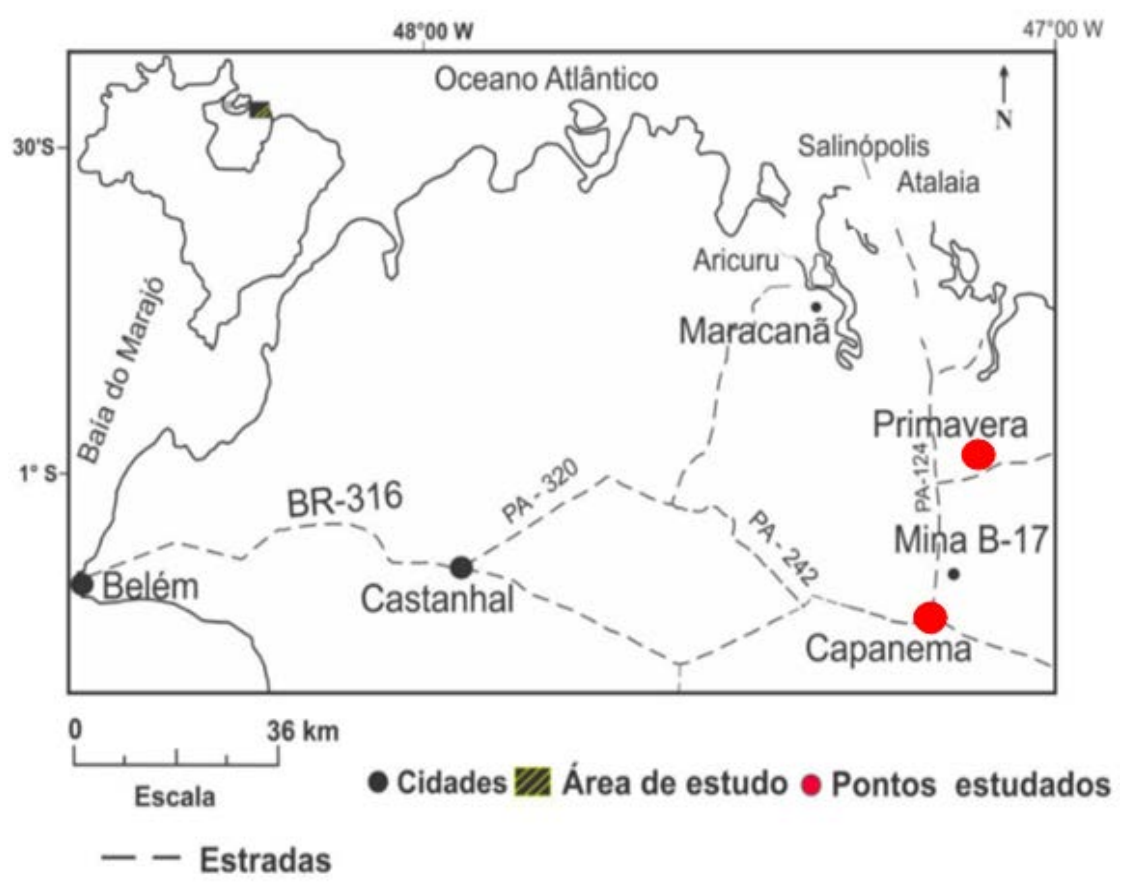

Figura 1 - Localização dos pontos estudados onde foram aplicadas as SEV’s. Mod. de Silva (2015). 


\section{CONTEXTO GEOLÓGICO}

O Mioceno foi um período geologicamente ativo, tendo testemunhado eventos como expansão de geleiras na Antártida, fechamento do mar Mediterrâneo e soerguimentos importantes em vários cinturões orogênicos de grande repercussão global Rossetti (2006).

A área de estudo selecionada para este trabalho é o nordeste do estado do Pará e apresentam um extenso registro Miocênico, nesta região foram identificadas predominantemente duas formações rochosas, Pirabas e Barreiras. Outra unidade que pode ser identificada em áreas não muito afetadas pelo intemperismo são os sedimentos do PósBarreiras. Os depósitos Miocênicos do nordeste do Pará ocorreram em diferentes contextos tectônicos, sendo particularmente bem exposto na Plataforma Bragantina.

A Plataforma Bragantina zona do embasamento com estabilidade tectônica, formada por rochas ígneas e metamórficas podendo ser observadas, por exemplo, na mina a céu aberto Santa Mônica localizada no município de Capanema-PA. A Plataforma Bragantina é limitada a leste pela Bacia Bragança-Vizeu, a oeste pela sub-Bacia Cametá e ao sul pelo Arco do Guamá Rossetti \& Góes (2004), são observáveis na Plataforma Bragantina as formações Pirabas e Barreiras, além dos sedimentos Pós-Barreiras.

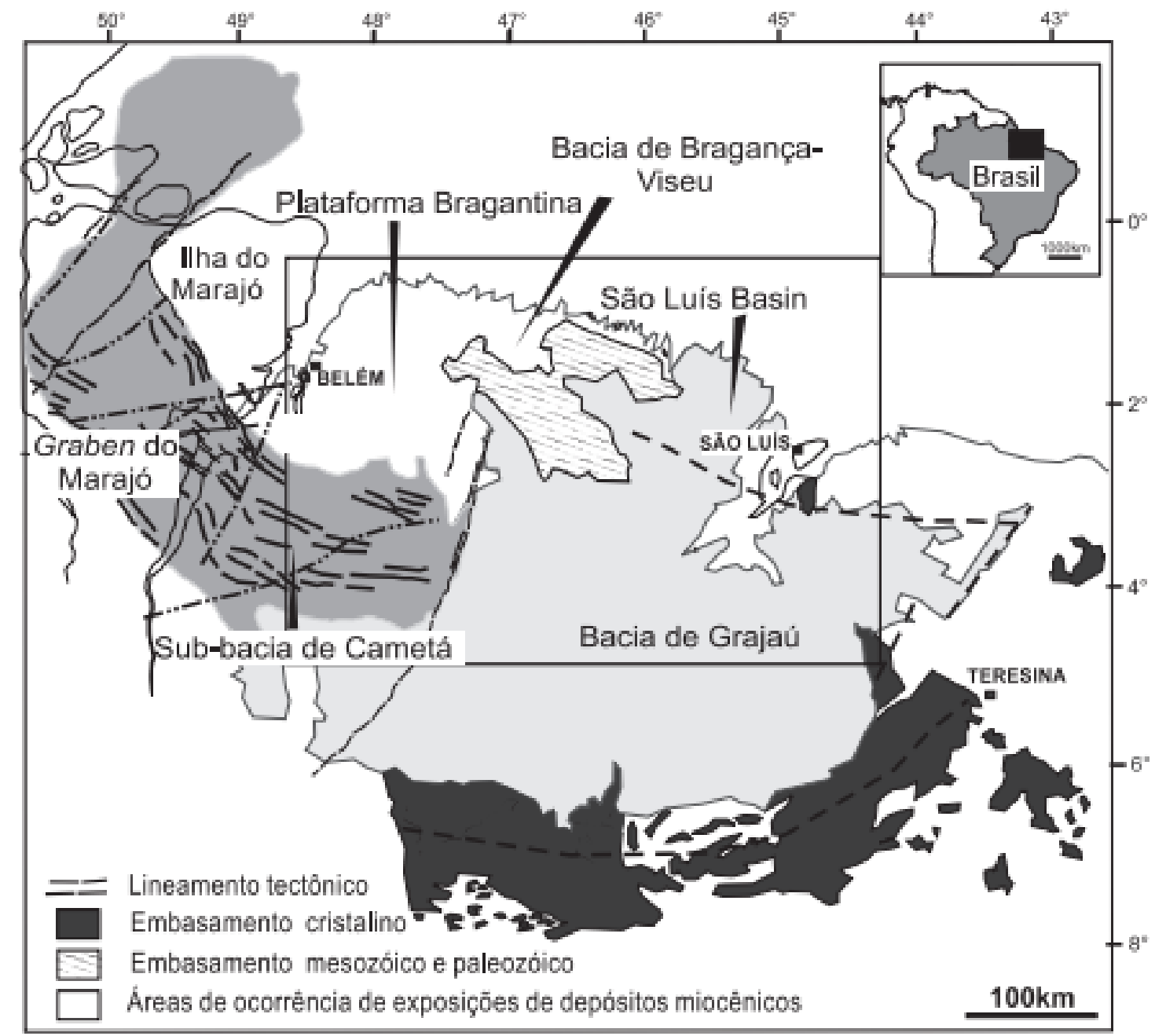

Figura 2- Mapa de localização dos depósitos miocênicos de parte da região norte do Brasil (Rosseti, 2006).

A figura abaixo mostra o contato entre a Formação Barreiras e a Formação Pirabas, no município de Capanema, onde a parte superior é composta por uma sequência de sedimentos detríticos, siliciclásticos, de origem fluvial e marinha (Arai, 2006).
A parte inferior é a Formação Pirabas, caracterizada por sedimentação carbonática, além de abundante conteúdo fossilífero como conchas, foraminíferos (Ferreira, 1966; Góes et al., 1990; Petri, 1954, 1957; Rossetti \& Góes, 2004). 


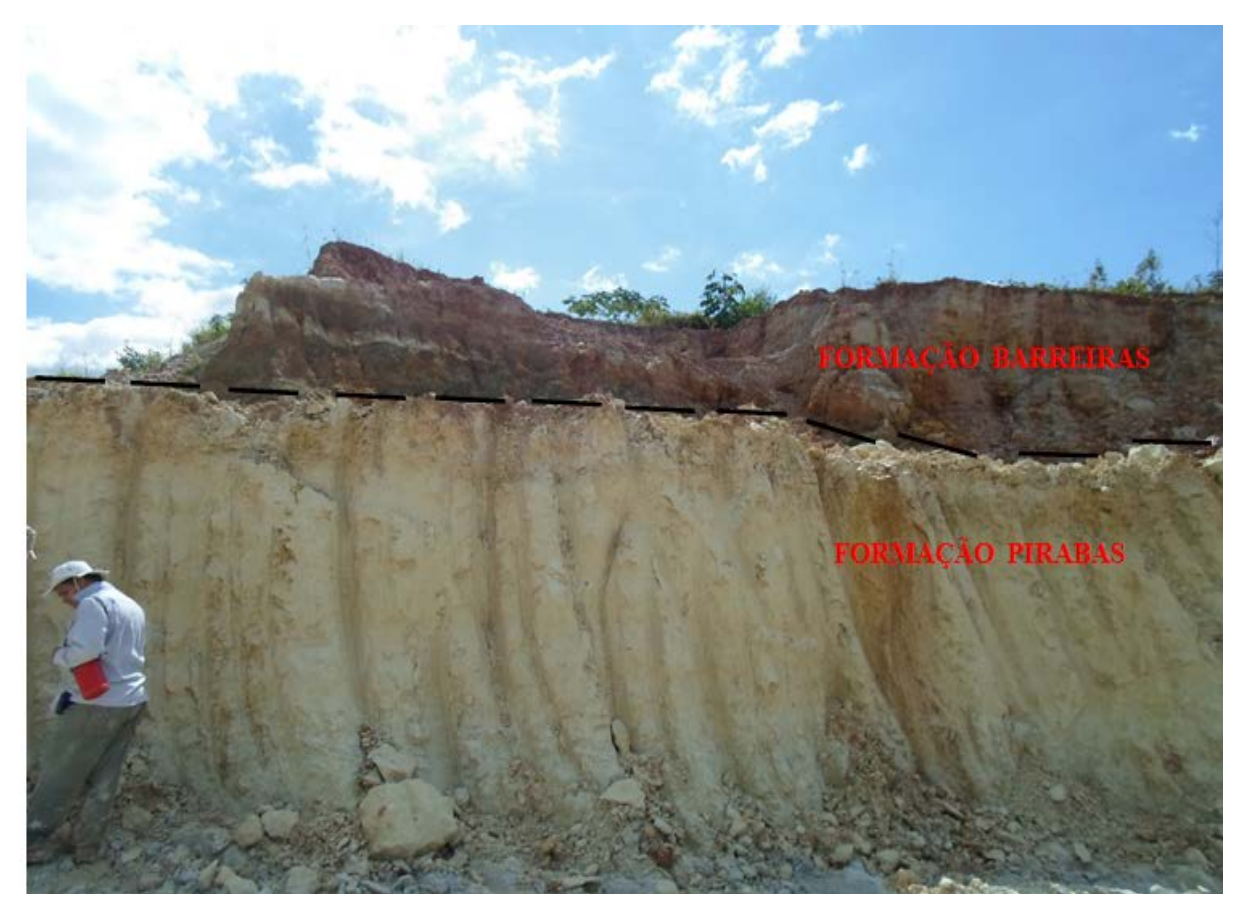

Figura 3 - Formação Barreiras sobreposta à Formação Pirabas no município de Capanema. A pessoa usada como escala tem aproximadamente $1,65 \mathrm{~m}$.

\section{METODOLOGIA E MATERIAIS}

\section{Método da Eletrorresistividade}

A eletrorresistividade é um dos métodos geofísicos que se destaca dentre os métodos geoéletricos, e tem o objetivo de determinar a resistividade elétrica dos materiais. Este método tem sido aplicado em diversas áreas como prospecção mineral, estudos ambientais, arqueologia, e em pesquisas de águas subterrânea.

Devido às rochas e os solos terem características elétricas e eletromagnéticas em seus variados tipos de materiais existentes no meio geológico é possível encontrar características como, por exemplo: litológias, deter- minação de contatos geológicos, descontinuidade de camadas, além de determinar possíveis localidades de aquífero na subsuperfície.

O método da eletroresistividade baseia-se fundamentalmente em medir a dificuldade da passagem de corrente elétrica (I) no meio através da injeção de corrente contínua em dois pontos do terreno (denominados de pontos $\mathrm{A}$ e B) e mede a diferença de potencial $(\Delta V)$ entre outros dois pontos (denominados de $\mathrm{M}$ e $\mathrm{N}$ ), como resultado da passagem da corrente injetada. A figura 4 ilustra a disposição dos eletrodos na aplicação do método na superfície do terreno.

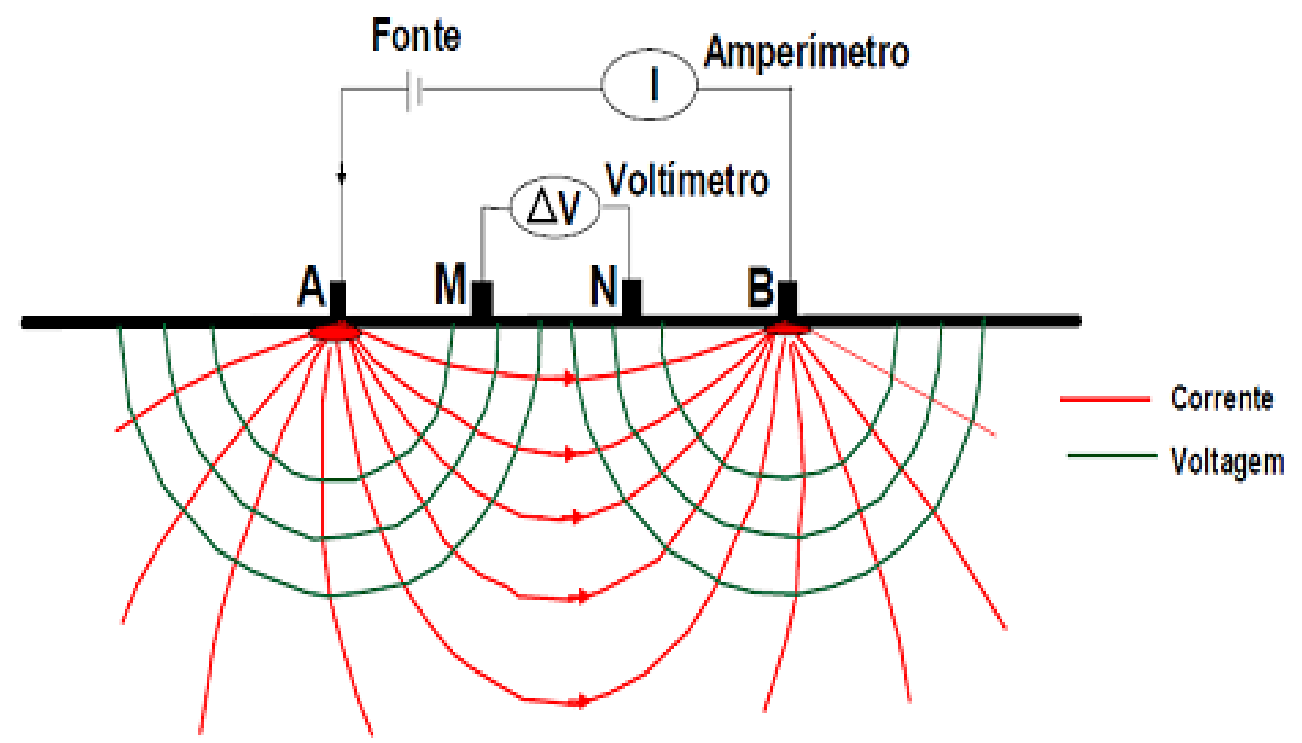

Figura 4 - Disposição dos eletrodos na superfície do terreno e fluxo de corrente (Freitas Filho, 2006). 
Conhecendo-se o valor da corrente injetada e da diferença de potencial é possível calcular a resistividade elétrica para um meio homogêneo e isotrópico através da seguinte expressão:

$$
\rho=K \frac{\Delta V}{I} \text { (ohm.m) }
$$

Em que:

$\rho \rightarrow$ Resistividade elétrica. [ $\Omega . m]$;

$\Delta \mathrm{V} \rightarrow$ Diferença de potencial elétrico medida entre $\mathrm{M}$ e N. [Volt];

$\mathrm{I} \rightarrow$ Corrente aplicada entre A e B. [Amper];

$\mathrm{K} \rightarrow$ Fator geométrico para o arranjo dos eletrodos AMNB, que é dado por:

$$
k=2 \pi\left(\frac{1}{\overline{A M}}-\frac{1}{\overline{B M}}-\frac{1}{\overline{A N}}+\frac{1}{\overline{B N}}\right)^{-1}
$$

Portanto, o uso do método da eletrorresistividade no campo, é baseado na capacidade do equipamento em introduzir uma corrente elétrica no subsolo a diferentes profundidades de investigação, e calcular as resistividades dos materiais geológicos a estas várias profundidades.

\section{Resistividade Aparente}

A resistividade verdadeira de um meio geológico considerado homogêneo e isotrópico pode ser calculada pela equação 1 . Entretanto, a terra não é homogênea e nem isotrópica, o valor da resistividade elétrica varia de ponto a ponto tanto em profundidade com lateralmente, consequentemente a resistividade elétrica varia ponto a ponto.

Contundo, esta resistividade 'aparente' obtida nos equipamentos para levantamentos de eletroresistividade não é propriamente um parâmetro físico do meio e sim um valor integrado do semi-espaço sobre o qual a medida é efetuada, então a resistividade aparente resulta de diversas influências existentes no volume investigado (Orellana, 1972).

O conceito de resistividade aparente é de grande utilidade em aplicações práticas do método eletrorresistividade, pois é um parâmetro que pode apresentar variações ao longo da subsuperfície, sendo diagnóstico da presença de heterogeneidades elétricas resistivas ou condutivas, o padrão da resistividade aparente associada a uma determinada estrutura em subsuperfície é geralmente complexo e comumente não corresponde aos valores de resistividade verdadeira. Então a equação 1 é mais bem representada:

$$
\rho a=K \frac{\Delta V}{I}(\text { ohm.m })
$$

\section{Sondagem Elétrica Vertical}

No método da eletroresistividade utiliza-se duas técnicas de investigação principais, o caminhamento elétrico, realizado ao longo de seção (horizontal), que investiga a variação lateral da resistividade a uma determinada profundidade e a sondagem elétrica vertical (SEV), que investiga a variação vertical da resistividade.

A técnica de sondagem elétrica vertical consiste basicamente, na análise e interpretação de um parâmetro físico, obtido a partir de medidas efetuadas na superfície do terreno, investigando de maneira pontual, sua variação em profundidade. Para o desenvolvimento desta técnica de investigação, diferentes procedimentos de campo podem ser adotados, levando ao mesmo fim. Esses procedimentos referem-se à disposição dos eletrodos necessários para a execução das técnicas, e são denominados de arranjos de desenvolvimento, os principais arranjos são Schlumberger e Wenner (Figura 5).

As medidas usando esses arranjos normalmente são tomadas ao longo de uma linha, definindo-se uma abertura ou espaçamento entre eletrodos. Quanto maior for esta abertura, maiores serão as profundidades alcançadas. A profundidade também está relacionada ao fator de separação entre os eletrodos de corrente e potencial.

No Arranjo Wenner os quatro eletrodos apresentam uma mesma separação, essa separação será denominada de 'a', crescente e constante durante todo o desenvolvimento do ensaio, sendo, deslocados simultaneamente, mantendo sempre a relação: $\mathrm{AM}=\mathrm{MN}=\mathrm{NB}=$ a, e o centro do arranjo permanece fixo. A resistividade aparente é calculada através da equação abaixo:

$$
\rho a=2 . \pi \cdot a \cdot \frac{\Delta \mathrm{V}}{I}(\mathrm{ohm} \cdot \mathrm{m})
$$

Onde o fator geométrico para esse tipo de arranjo é: $K=2 \pi \cdot a$

O Arranjo Wenner oferece bons resultados no mapeamento de estruturas horizontais, pois é relativamente sensível a variações verticais de resistividade em subsuperfície fornecendo, desta forma, uma boa resolução vertical. No entanto, apresenta baixa sensitividade para variações horizontais de resistividade não tendo, portanto, bom desempenho na definição de estruturas estreitas e verticais (resolução 
lateral) (Gandolfo, 2007). Dados obtidos com Arranjo Wenner são menos afetadas por variações superficiais de resistividade se comparados aqueles obtidos por outros arranjos, contudo, a principal vantagem do Arranjo Wenner está na elevada razão sinal/ruído que fornece.

Porém, uma desvantagem do arranjo é a rápida perda da cobertura com a profundidade, à medida que se aumenta o espaçamento entre os eletrodos, ou seja, buscando maiores profundidades de investigação a cobertura horizontal da subsuperfície diminui significativamente, esta característica pode ser crítica em levantamentos realizados em locais com pouca disponibilidade de espaço.

No caso do Arranjo Schlumberger a ideia básica é fazer com que à distância que separa os eletrodos de potencial $\mathrm{M}$ e $\mathrm{N}$ se mantenha fixa e tenda a zero em relação à distância crescente dos eletrodos de corrente. No desenvolvimento de uma SEV usando o Arranjo Schlumberger, ao introduzir no subsolo a corrente elétrica (I) por meio dos eletrodos A e B, resulta que entre os eletrodos $\mathrm{M}$ e $\mathrm{N}$ mede-se a diferença de potencial $(\Delta \mathrm{V})$ criada. As medidas obtidas são utilizadas para o cálculo da resistividade aparente, utilizando-se as equações:

$$
\rho a=k \cdot \frac{\Delta V}{I}(\text { ohm } \cdot \mathrm{m})
$$

Em que o fator geométrico é:

$$
K=\pi\left(\frac{a^{2}}{b}-\frac{b}{4}\right)
$$

Onde:

$a=$ espaçamento do arranjo $\mathrm{AB} / 2$ e $b=$ separação dos eletrodos de potencial.

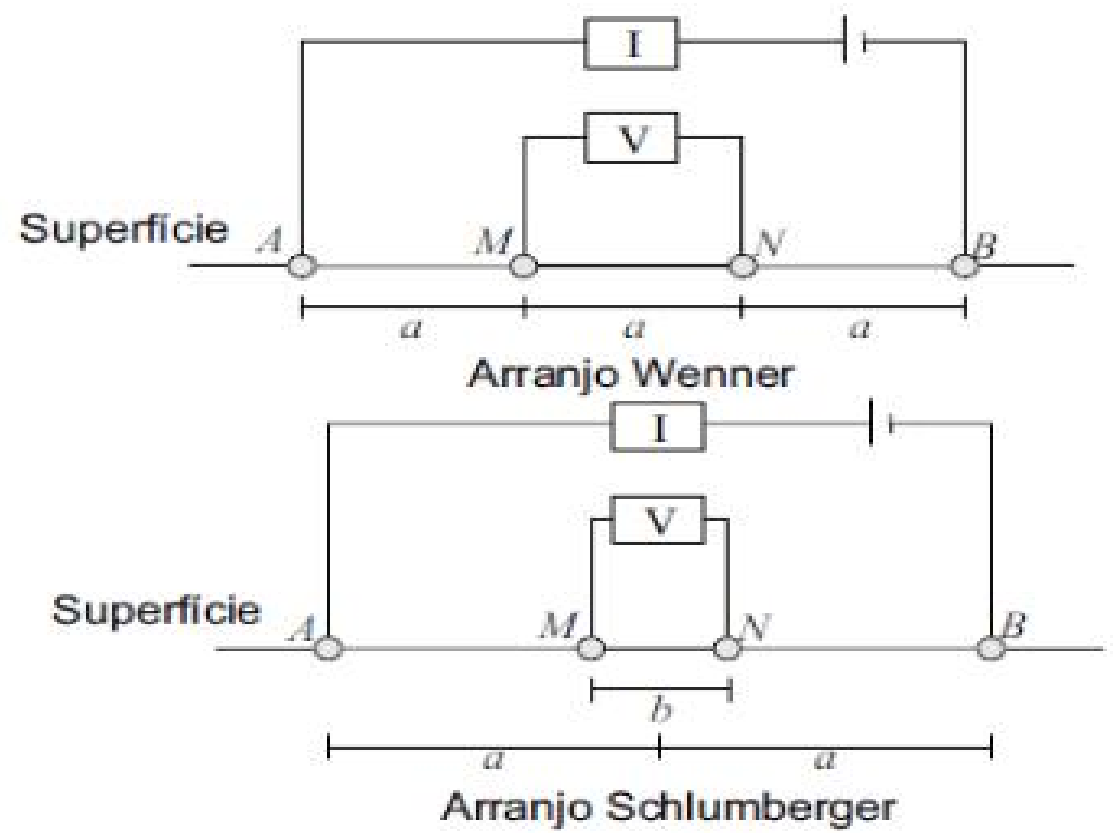

Figura 5 - Arranjo Wenner e Arranjo Schumberger. (Segundo http://www.ebah.com.br/content/ ABAAAga3kAE/ diagrafia-eletrica 2017).

\section{Descrição do Equipamento}

$\mathrm{O}$ equipamento utilizado para o desenvolvimento deste trabalho foi o Geotest Rd -1000 (Figura 6), de fabricação brasileira, ele é composto por um transmissor de corrente Geotest Rd - 1000 TX, que é conectado em duas baterias em série somando 24 volts, e outro suporte receptor Geotest Rd - $1000 \mathrm{RX}$, este é alimentado por um conjunto de oito baterias de tamanho AA de 1,2 volts. O equipamento tem o seguinte funcionamento:

Primeiro temos que conectar todos os cabos de forma correta, verificado, damos a partida no equipamento, ele aplica uma corrente no solo através dos eletrodos de corrente, enviando um pulso de tensão de polaridade positiva e outro com polaridade negativa. O objetivo é evitar a polarização dos eletrodos, o equipamento tem um pulso de tensão que pode variar de 5 a 800 volts.

Já para os eletrodos de potencial o equipamento Geotest Rd - 1000 discrimina as tensões telúricas assim como as tensões de contato existentes e integra somente as tensões devidas à resposta aos pulsos de correntes que foram emitidos através dos eletrodos, obtendo desse modo a tensão $\Delta \mathrm{V}$.

Em campo foram utilizados somente quatro eletrodos de metal, e quatro bobinas, duas para 
os transmissores de corrente e duas para os receptores de potencial. Os eletrodos de corrente são geralmente de aço (latão) ou de cobre, os quais são enterrados parcialmente no solo. Para áreas secas faz-se necessário a utilização de uma substância composta por água e sal em torno dos eletrodos, para melhorar o contato do eletrodo com o solo. Já para os cabos, recomenda-se usar cabos finos, exceto quando é necessária corrente muito forte. É importante usar um isolamento de alta qualidade para evitar a fuga de energia, por serem umas das primeiras fontes de erro nas medições de resistividade.

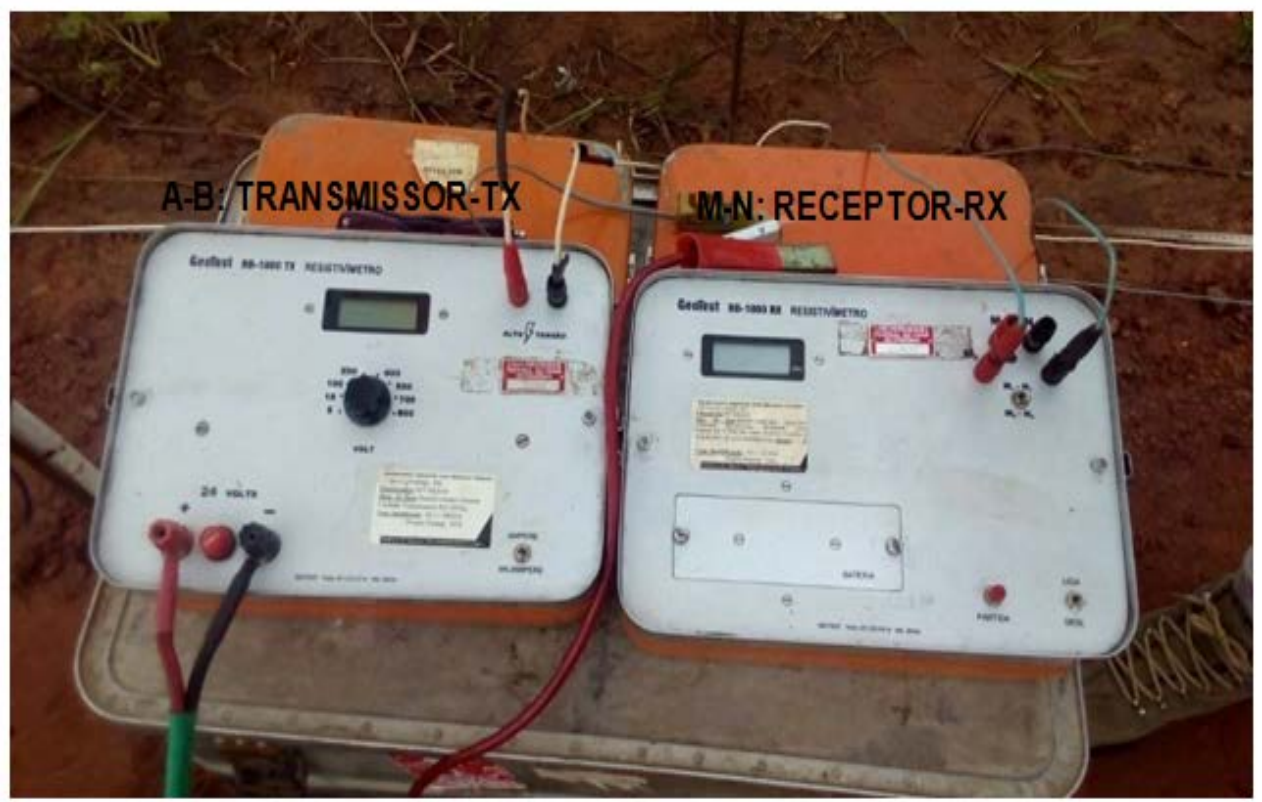

Figura 6 - Resistivímetro Geotest Rd - 1000.

\section{Dados de Poços}

A seguir serão apresentadas informações relativas aos dados de poços, que foram utilizados para calibrar as SEVs, para fazermos diversas correlações entre as informações geológicas provenientes dos poços com os dados geofísicos adquiridos. Esses dados de poços foram obtidos na plataforma online do Sistema de Informação de Águas Subterrâneas (SIAGAS).

Todos os dados de poços disponíveis pelo sistema são encontrados a partir de numerações, como podemos observar na figura 7. Para a área de interesse deste trabalho foram analisados e selecionados poços objetivando escolher aqueles que oferecem informação a respeito da profundidade do embasamento.

Os poços de interesse vieram em forma de relatórios trazendo informações de localização, litologia, profundidade dentre outras não relevantes para nosso estudo. Então, iniciamos uma pesquisa nos poços nas áreas de interesse, com intuito de encontrar poços que alcançasse a base da Formação Pirabas ou até mesmo rochas características do embasamento, porém, só foi possível encontrar um poço que atingiu a base da Formação Pirabas, este poço está localizado na cidade de Capanema. No caso de Primavera não tem poços com a profundidade da base da Formação Pirabas, então foi escolhido um poço que apresentavam rochas características desta formação.

O poço escolhido para o município de Capanema (figura 8) encontra-se em um local chamado Caixa d'água. Este foi selecionado, pois o perfil construtivo do poço apresenta uma profundidade de aproximadamente 72 metros, e as unidades descritas, na sua seção litológica, bem como suas espessuras e a informação da profundidade de contato entre a Formação Pirabas e o embasamento, são descriminadas com base na ficha técnica do poço.

No topo do perfil ocorre uma camada de solo areno-argiloso amarelo avermelhada (0 $0,5 \mathrm{~m})$, abaixo ocorre uma camada de argila calcífera amarela $(0,5$ - $8 \mathrm{~m})$, depois uma camada de areia calcífera cinza esbranquiçado (8 - $17 \mathrm{~m})$, calcário cinza $(17-34 \mathrm{~m})$, argila arenosa cinza esbranquiçada (34 - $50 \mathrm{~m})$, rochas intemperizadas e decompostas cinza (50 - 70 $\mathrm{m})$, e na base do perfil temos rocha cristalina não identificada cinza (70 - $72 \mathrm{~m})$. 


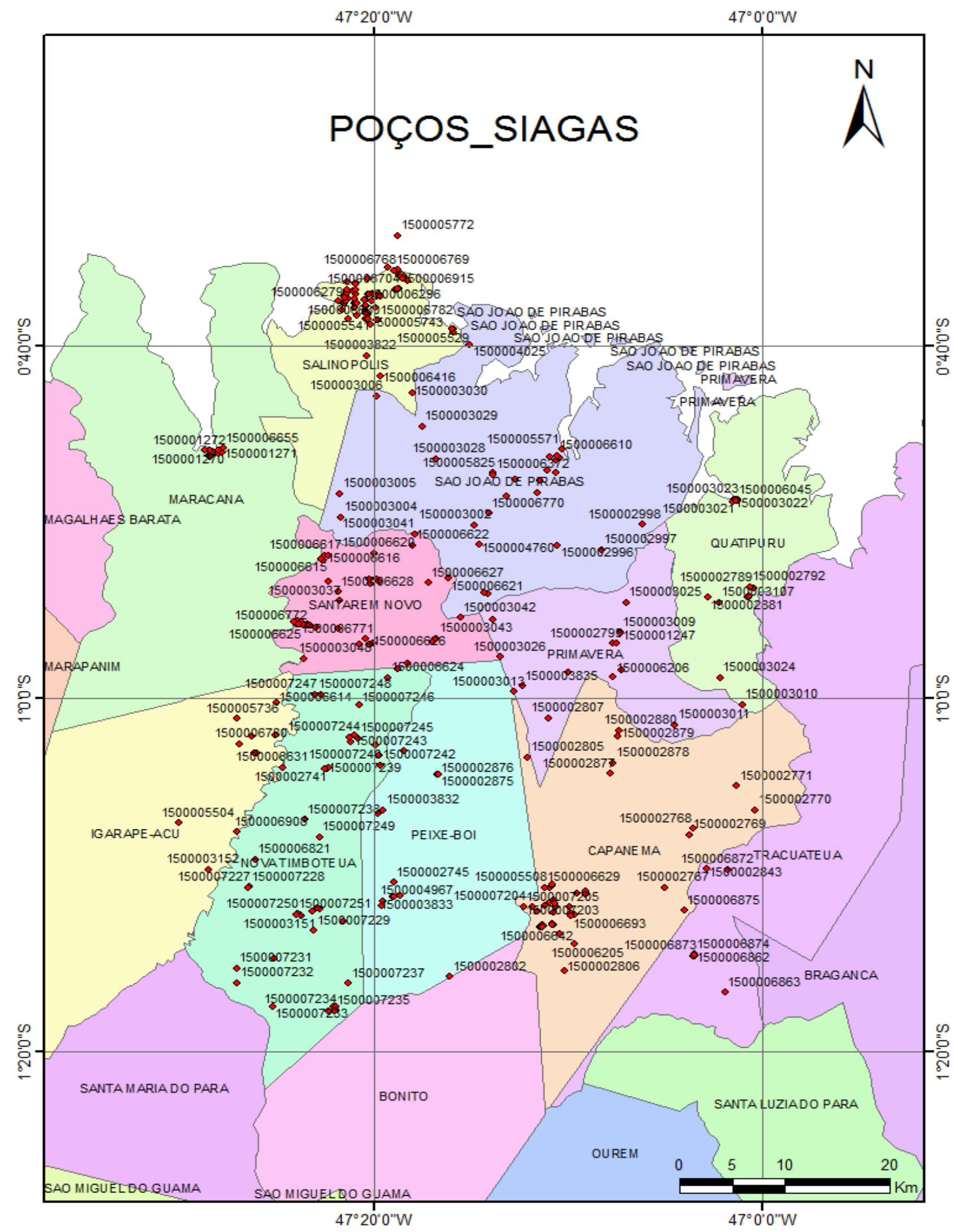

Figura 7 - Localização dos poços dentro da região de interesse. Fonte: (Vieira, 2015).

O poço escolhido para o município de Primavera (figura 9) encontra-se em um local chamado Bacabal. Este foi selecionado, pois contêm rochas características da Formação Barreiras e da Formação Pirabas. O perfil construtivo do poço apresenta uma profundi- dade de aproximadamente 21 metros, e as unidades descritas, na sua seção litológica, bem como suas espessuras, são descriminadas com base na ficha técnica do poço. No topo do perfil ocorre uma camada de solo de cor amarelo amarronzado (0 - $2 \mathrm{~m}$ ) de profundidade, abaixo 
ocorre uma camada de areia argilosa de cor amarelo alaranjado (2 - $9 \mathrm{~m}$ ) de profundidade, depois uma camada de areia calcífera de cor amarela avermelhado (9 $\quad-12$ m) de profundidade, arenito calcífero de cor amarelo amarronzado (12 - $18 \mathrm{~m}$ ) de profundidade, e na base do perfil temos rocha calcário de cor cinza amarelado a (18- $21 \mathrm{~m})$ de profundidade.

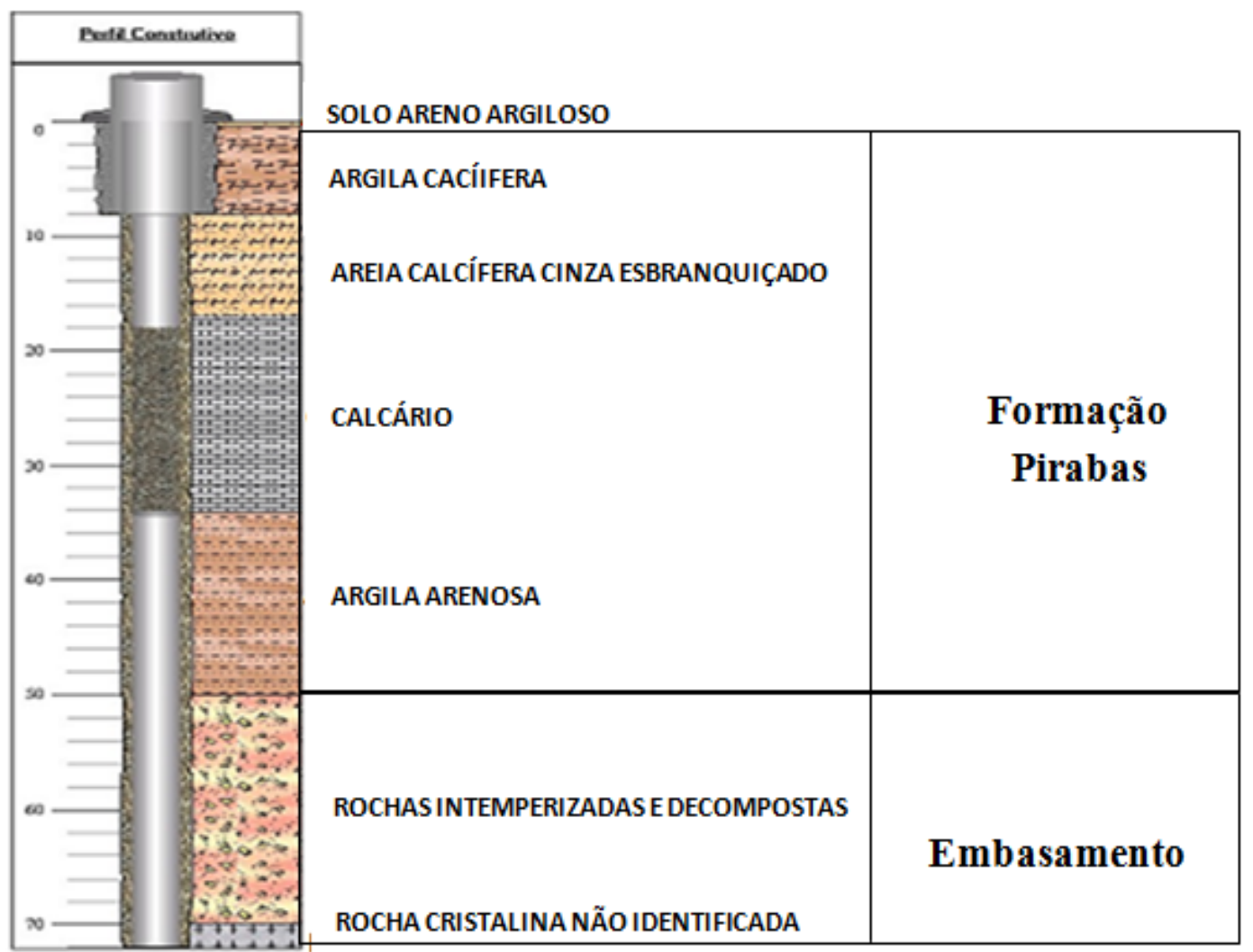

Figura 8 - Perfil litológico do poço no município de Capanema (Mod. do SIAGAS 2017).

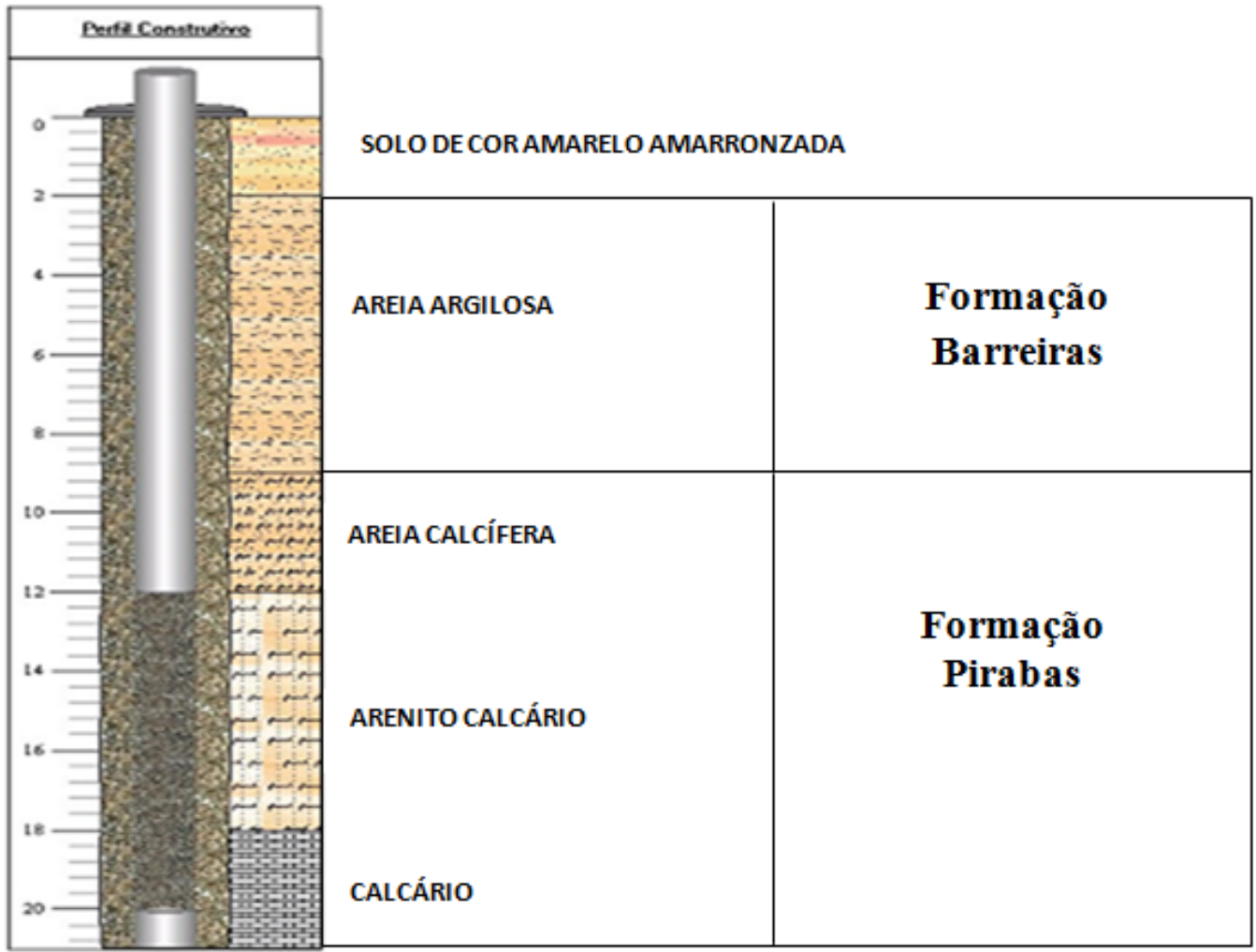

Figura 9- Perfil litológico do poço no município de Primavera (Mod. do SIAGAS 2017). 


\section{LEVANTAMENTO GEOFÍSICO}

\section{Municípios de Capanema e Primavera}

Foram realizadas duas sondagens elétricas verticais (SEVs), a primeira realizada no período da manhã no município de Capanema e outra realizada à tarde no município de Primavera, ambas no dia 16 de fevereiro de 2017, isto foi possível devido às proximidades entre as duas cidades.

Em Capanema a SEV foi realizada ao longo de uma estrada de terra com Latitude $1^{\circ} 10^{\prime} 24.3^{\prime \prime S}$ e Longitude $47^{\circ} 08^{\prime} 37.6^{\prime \prime} \mathrm{W}$, próximo a uma localidade chamada Caixa d' água e em Primavera a SEV também foi realizada ao longo de uma estrada de terra com Latitude $0^{\circ} 53$ '39.0"S e Longitude 4706'34.5"W, próximo a uma localidade chamada Bacabal.

As sondagens foram realizadas nessas localidades, pois ficavam próximas de dados de poços disponíveis na plataforma online do Sistema de informação de águas subterrâneas (SIAGAS).

Esses poços contêm dados litológicos e um perfil construtivo especificando o tamanho das camadas e suas descrições litológicas.

As condições operacionais, de um modo geral, não foram muito favoráveis pelo fato do ambiente ser altamente condutivo, tanto em Capanema como em Primavera, estes ambientes condutivos contribuíram para que a profundidade de investigação fosse baixa, já que a corrente tem dificuldade de penetrar em ambientes condutivos, além disso, provoca elevados valores de corrente e baixo valor de potencial.

As localizações das SEVs são mostradas nas figuras 10 e 11 . As sondagens elétricas verticais foram executadas com o Arranjo Wenner com um perfil de $480 \mathrm{~m}$ na horizontal, então a separação máxima entre os eletrodos é igual a $160 \mathrm{~m}(\mathrm{a}=160 \mathrm{~m})$.

Durante as tomadas das medidas, tanto em Capanema quanto em Primavera, foi necessário a utilização de duas fitas métricas, e diversos piquetes para marcar as medições, pois é muito importante manter os espaçamentos entre os eletrodos de potencial e de corrente iguais, pois pode influenciar na leitura do $\Delta \mathrm{V}$.

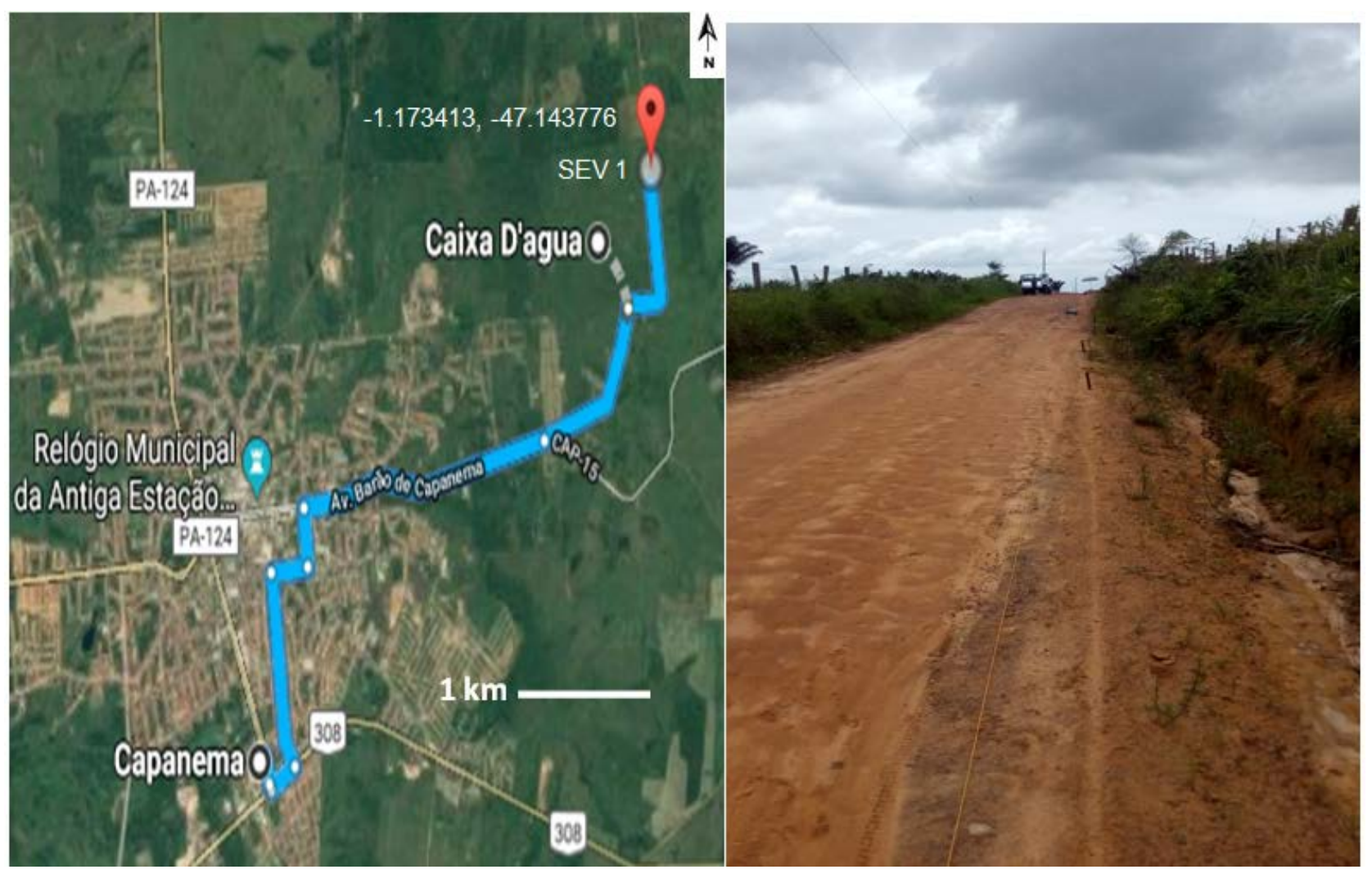

Figura 10 - Local do levantamento no município de Capanema (Modificado do Google Maps 2017). 

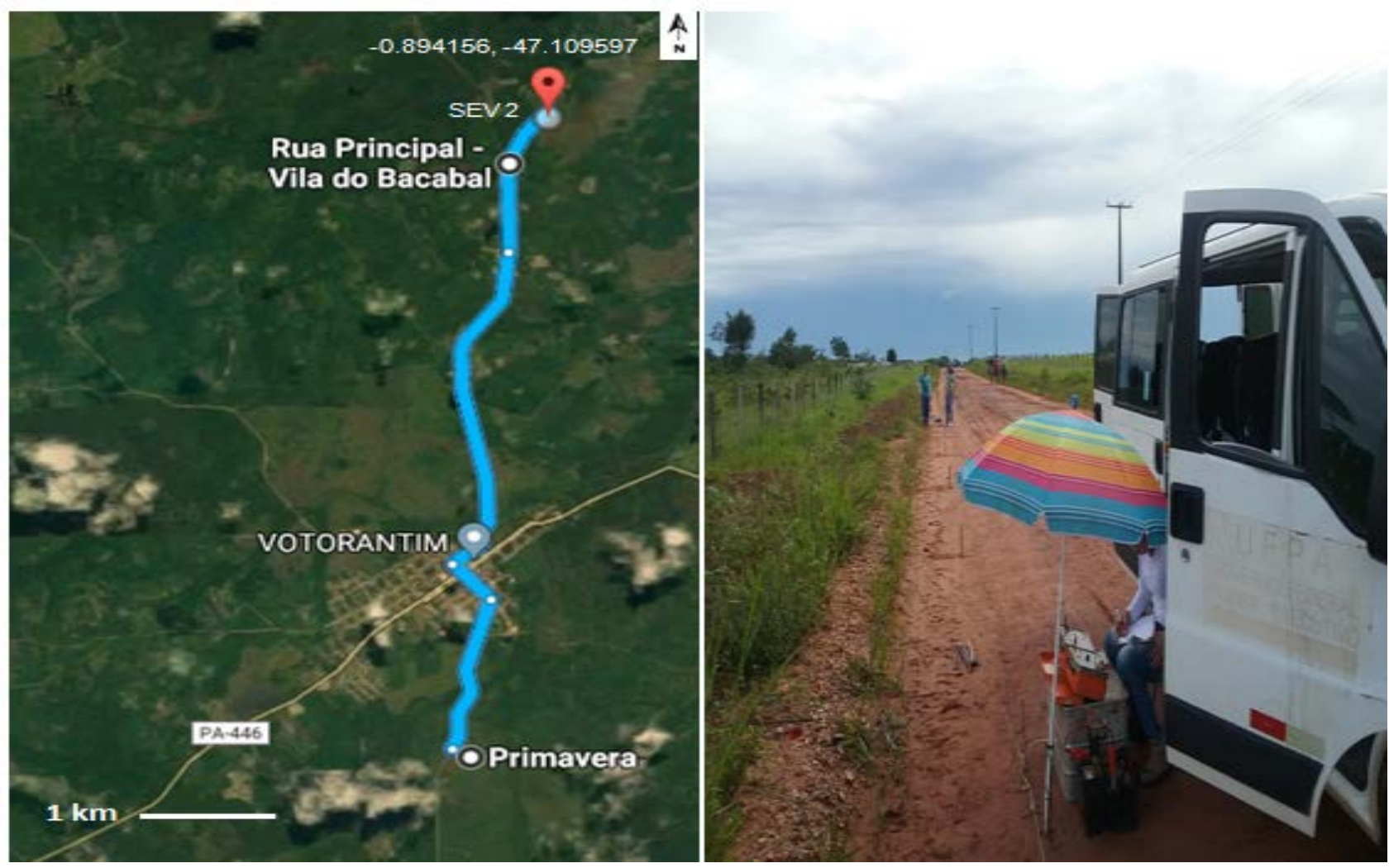

Figura 11 - Local do levantamento no município de Primavera (Mod. do Google Maps 2017).

\section{RESULTADOS E INTERPRETAÇÃO}

As medidas de resistividades foram obtidas aplicando um processo de inversão nos dados das sondagens elétricas. Esta inversão corresponde a um modelo provável de distribuição de resistividade em subsuperfície e modelos de estruturas geológicas. As medidas de resistividades também podem ser apresentadas e interpoladas (contorno de isovalores) sob a forma de pseudosecões.

Os dados das SEVs foram invertidos através do programa IPI2win (Geoscan-M Ltda). O IPI2Win é projetado para realizar inversões 1D automáticas em dados de SEVs e/ou polarização induzida (IP). Nele foram inseridas as medidas obtidas em campo para gerarmos uma curva de resistividade aparente onde se tentou ajustar a curva calculada à curva gerada pelos dados. Para um melhor ajuste, introduziuse um número de camadas suficiente para que as curvas coincidam o máximo possível e diminua o erro quadrático médio (root mean square-RMS). O número de camadas pode ser introduzido manualmente ou automaticamente, sendo que o ajuste lateral influência na espessura da camada e o ajuste vertical na resistividade.

As sondagens elétricas foram representadas na maneira convencional, em curva bilogaritímico, com a resistividade aparente ( $\rho$ a) no eixo vertical e a separação de eletrodos no eixo horizontal. As curvas das SEVs, que representam variação de resistividade com a profundidade, foram suavizadas para corrigirem-se as descontinuidades originadas pela mudança de posição dos eletrodos.

Nos ambientes geológicos relativamente simples, envolvendo camadas horizontais, estimativas de profundidade de suas interfaces de separação podem ser feitas com o auxílio das informações geológicas disponíveis (dados de poços), o que permitiu o estabelecimento de um modelo satisfatório para a estratificação com vínculos de espessura. Essa metodologia foi usada na interpretação das SEVs, sendo as espessuras dos modelos, aqui analisados, obtidos a partir de perfis litológicos conhecidos, que se localizam próximos ao centro das SEVs.

\section{Resultado da SEV - Capanema}

Os resultados dos dados de campo são expostos em curvas logarítmicas (Figura 12) para uma melhor interpretação, deve-se ao fato das variações das estruturas geoelétricas representativas serem realçadas. Adotou-se também a estratégia de executar sondagens 
elétricas adjacentes a poços de perfis litológicos conhecidos. As interpretações destas sondagens foram feitas fixando-se os valores de espessuras das camadas (fornecidas pelos perfis litológicos) e estimando-se as resistividades, de maneira a ajustar a curva usando intervalos de valores característicos das respectivas litologias.

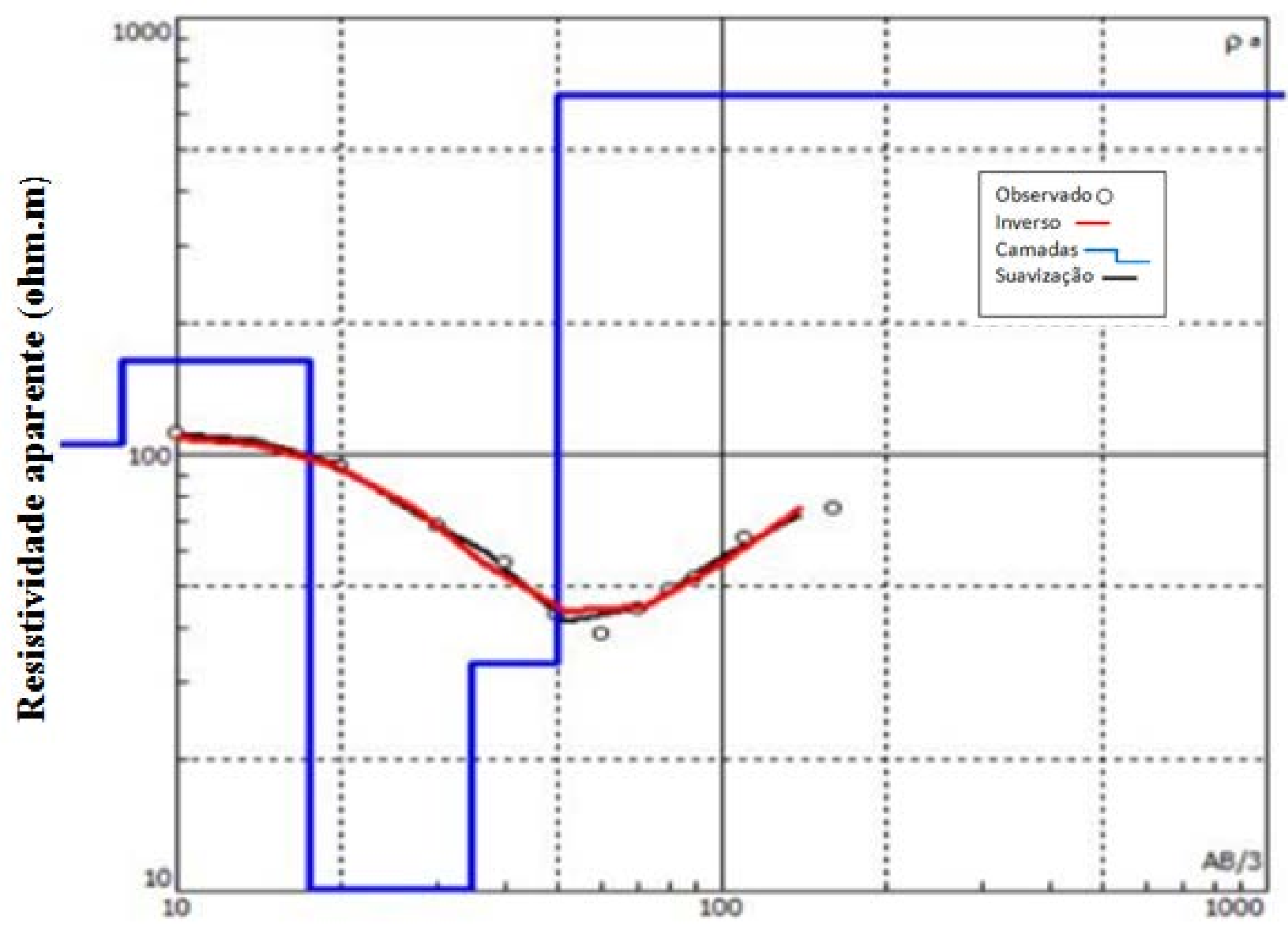

\section{Profundidade (m)}

Figura 12 - Interpretação da SEV1 utilizando o programa IPI2Win.

O modelo apresenta cinco camadas inseridas manualmente e um substrato com $\rho 1<\rho 2>\rho 3$ $<\rho 4<\rho 5$. O ajuste possui um erro quadrático médio de $3,36 \%$. A tabela a serguir é o modelo que fornece informacões como: parâmetros de resistividade $(\rho)$, espessura da camada (h), profundidade (d) e altimetria (Alt) diferença de nível. O valor negativo de Alt deve-se ao fato de que o programa admite $\mathrm{Z}$ negativo para baixo (profundidade).

Tabela 1 - Modelo geoelétrico do município de Capanema.

\begin{tabular}{|c|c|c|c|c|c|}
\hline \multicolumn{4}{|c|}{ 用 RMS=3.36\% } & \multicolumn{2}{|c|}{\begin{tabular}{|l|l|}
$\square$ & 回 \\
\end{tabular}} \\
\hline $\mathbf{N}$ & 1 & 2 & 3 & 4 & 5 \\
\hline$p$ & 106 & 164 & 10.1 & 33.2 & 665 \\
\hline h & 7.93 & 9.55 & 17.2 & 15.2 & \\
\hline d & 7.93 & 17.5 & 34.7 & 50 & \\
\hline Alt & -7.935 & -17.46 & -34.72 & -49.95 & \\
\hline
\end{tabular}


A Figura 13 abaixo é modelo geoelétrico e o perfil geológico correlacionados, onde foi possível determinar a distribuição espacial das

\section{PERFIL GEOLÓGICO}

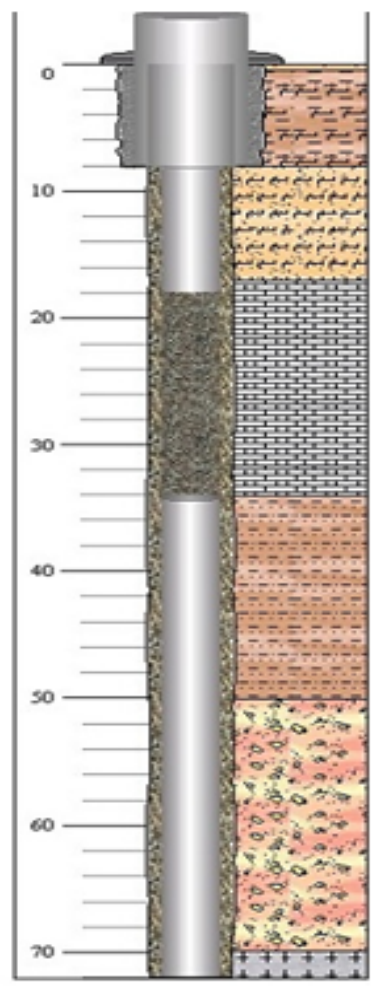

resistividades no subsolo, partindo dos dados das curvas de campo observados na superfície do terreno.

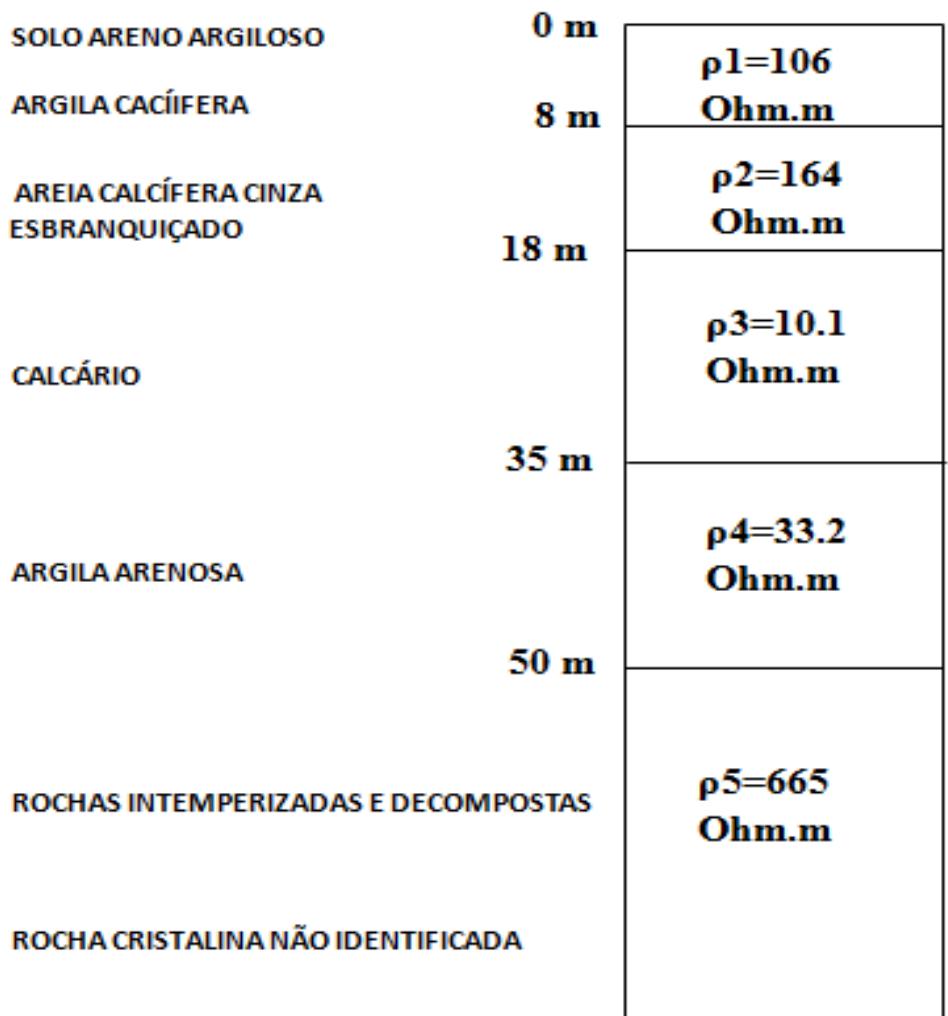

Figura 13 - Correlação da SEV 1 com o Poço litológico (Mod. do SIAGAS 2017).

Os principais horizontes geológicos mostraram-se influentes na sondagem. $O$ modelo proposto envolve inicialmente uma primeira camada de aproximadamente $8 \mathrm{~m}$, constituída de solo areno-argiloso e de argila calcífera, com 106 ohm.m de resistividade, o solo areno-argiloso são sedimentos geralmente com bastante matéria orgânica, e é a camada mais superficial, enquanto que a argila calcífera é característica da Formação Pirabas.

A segunda camada com uma espessura entorno de $10 \mathrm{~m}$ é constituída por areia calcífera e 164 ohm.m de resistividade, possivelmente está camada é da Formação Pirabas, pois esta areia calcífera cinza esbranquiçada é o calcário mais fragmentado.

O terceiro pacote é composto de calcário com profundidade aproximadamente de $35 \mathrm{~m}$ e $10.1 \mathrm{ohm} . \mathrm{m}$ de resistividade, característicos da Formação Pirabas e de acordo com a ficha técnica do poço é onde se encontra o aquífero, pois devido sua resistividade está abaixo dos valores característicos para essa rocha.

A quarta camada é composto de argila- arenosa está a uma profundidade de 50 m e resistividade de 33.2 ohm.m., sua baixa resistividade é devido as soluções salinas presente na camada e finalmente, a quinta camada que representa o substrato com valor de resistividade de 665 ohm.m., sua resistividade alta se deve à falta de soluções salinas e possivelmente são rochas características do embasamento cristalino.

\section{Resultado da SEV - Primavera}

Os resultados dos dados de campo estão em curvas logarítmicas (Figura 14). Adotou-se também a estratégia de executar sondagens elétricas adjacentes a poços de perfis litológicos conhecidos. As interpretações destas sondagens foram feitas fixando-se os valores de espessuras das camadas (fornecidas pelos perfis litológicos) e estimando-se as resistividades, de maneira a ajustar a curva usando intervalos de valores característicos das respectivas litologias.

O modelo (linha azul) de 3 camadas inseridas manualmente com $\rho 1<\rho 2<\rho 3$. O ajuste possui um erro de $4,07 \%$. A tabela a 
seguir mostra os parâmetros de resistividade $(\rho)$, espessura da camada $(\mathrm{h})$, profundidade $(\mathrm{d})$ e altimetria (Alt) diferença de nível. O valor negativo de Alt deve-se ao fato de que o programa admite $\mathrm{Z}$ negativo para baixo (profundidade).

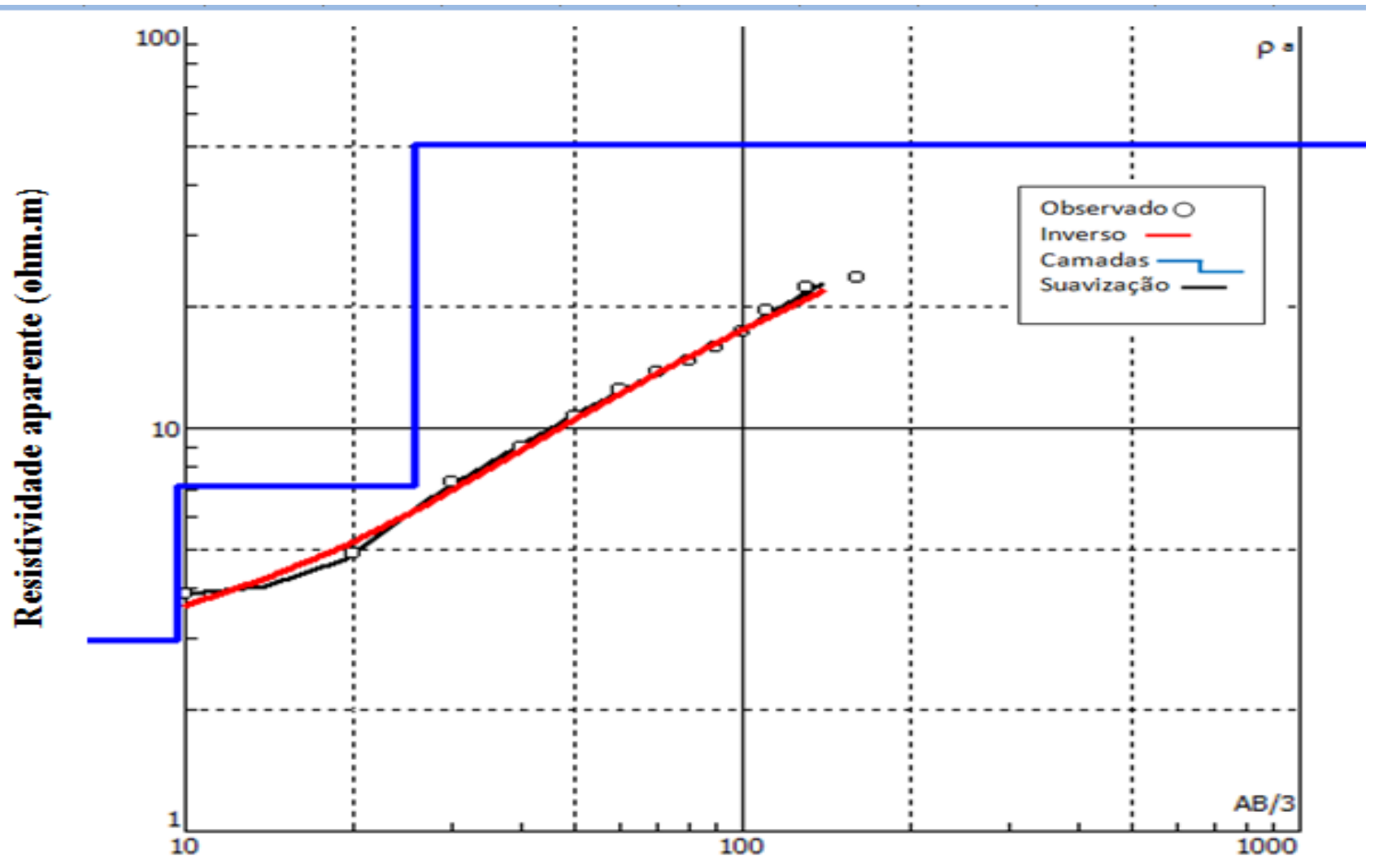

Profundidade (m)

Figura 14 - Interpretação da SEV 2 utilizando o programa IPI2Win.

Tabela 2 - Modelo geoelétrico do município de Primavera.

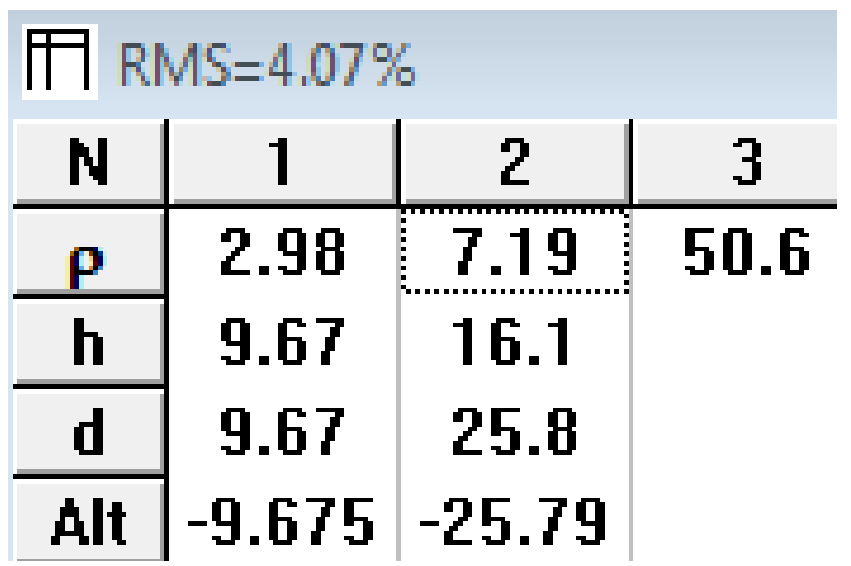

A Figura 15 mostra o modelo geoelétrico e o perfil geológico correlacionados, onde foi possível determinar a distribuição espacial das resistividades no subsolo, partindo dos dados das curvas de campo observados na superfície do terreno.

Em Primavera o comportamento da curva mostrou a presença de sedimentos mais condutivos em todas as camadas, pois segundo as informações da ficha técnica do poço o nível do aquífero é raso em torno de $12 \mathrm{~m}$ de profundidade, além de estarmos no período chuvoso na região, provocando a alta saturação do meio estudado.

A primeira camada de aproximadamente $9 \mathrm{~m}$ com um pacote de duas camadas composta por solo de cor amarela amarronzada e areia argilosa, com resistividade de 2,98 ohm.m, a 
areia argilosa são sedimentos característicos da Formação Barreiras. O segundo pacote é constituído por areia calcífera, arenito calcífero e calcário com uma camada de espessura de 16

\section{PERFIL GEOLÓGICO}

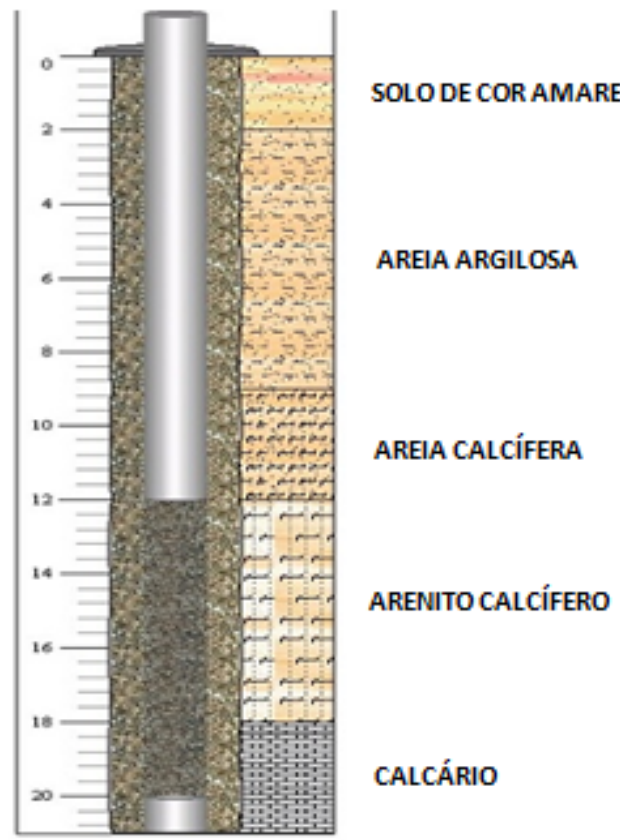

m, sedimentos característico da Formação Pirabas. E finalmente, a quinta camada que representa o substrato com valor de $\begin{array}{llll}\text { resistividade de } & 50.6 & \text { ohm.m. }\end{array}$

\section{MODELO GEOELÉTRICO}

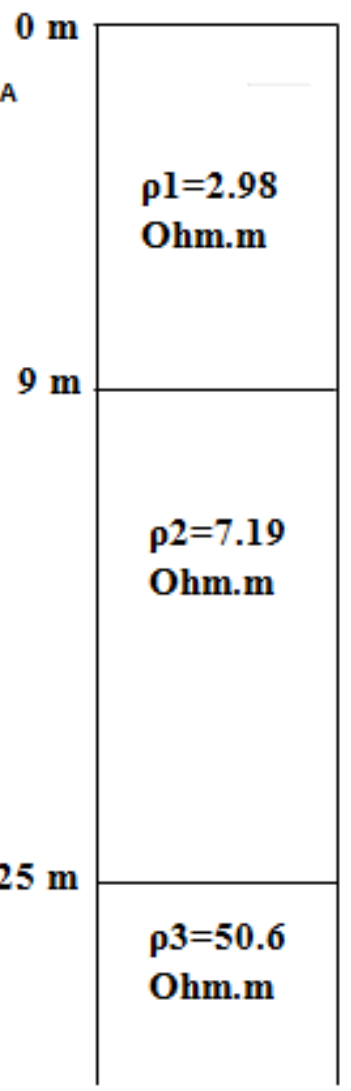

Figura 15 - Correlação da SEV 2 com o poço litológico (Mod. do SIAGAS, 2017).

As respostas obtidas com as sondagens elétricas verticais tanto em Capanema como em Primavera mostram valores de resistividade baixos.

Tal fato decorre dos ambientes estudados serem altamente condutivo, devido à presença de soluções salinas que ocupam os poros das camadas e além disso as sondagens elétricas verticas foram feitas em um período bastata chuvoso nessas regiões, entretanto, a correlação entre os valores de resistividade com os perfis litológicos é eficiente.

\section{CONCLUSÃO}

A caracterização do cenário geológico da região continental do nordeste do estado do Pará é importante para conhecer melhor a dinâmica dos estratos deposicionais (Formação Barreiras e Formação Pirabas). A aplicação do método geofísico elétrico no estudo das unidades sedimentares continentais descritas neste trabalho foram uma tentativa de avaliar a efetividade do método neste tipo de ambiente, para auxiliar no mapeamento geológico sem perturbar o meio, e realizando o trabalho a custos mais baixos. Os resultados da integração dos dados geofísicos e geológicos permitiram elaborar as seguintes conclusões:

A aplicação do método eletrorresistividade nos municípios de Capanema e Primavera mostrou-se eficiente através de sondagens elétricas verticais para estabelecer valores de resistividade e espessura das camadas dos sedimentos característicos da Formação Barreiras e da Formação Pirabas e o possível contato do embasamento com a Formação Pirabas em Capanema, devido seus fortes contrastes de resistividades.

Para o município de Capanema a interpretação dos dados mostrou um forte 
contraste de resistividade a uma profundidade em torno de 50 metros, infere que possivelmente seja o topo do embasamento cristalino devido seu elevado valor de resistividade elétrica, além de localizar a uma profundidade em torno de 18 metros, um aquífero que correspondente a camada de calcário, cujo valor de resistividade está abaixo dos valores característico para essa rocha, possivelmente devido esta apresentar fraturas, consequentemente maior circulação de fluidos (soluções salinas), que ocupam os seus poros. Enquanto, que em Primavera o comportamento da curva mostrou a presença de sedimentos mais condutivos nas primeiras camadas, pois estamos no período chuvoso na região, provocando a alta saturação do meio estudado. Em geral, as correlações entre os valores de resistividade aparente com os perfis litológicos foram satisfatórios para identificar os contrastes de resistividade das Formações Barreiras e Pirabas e possivelmente o embasamento cristalino.

Para trabalhos futuros no local, recomendase aumentar os números de SEVs num mesmo município, com o objetivo de contribuir com mais informações a respeito da disposição das unidades litológicas, além de sondagens elétricas verticais com maiores aberturas dos elétrodos, em torno de 1000 metros para alcançar maiores profundidades de investigação.

\section{AGRADECIMENTOS}

Ao Conselho Nacional de Desenvolvimento Científico e Tecnológico (CNPQ) pelo financiamento do projeto de estudo paleoambiental e paleogeográfico da Formação Pirabas (Paleógeno-Neógeno) com base em dados estratigráficos, paleontológicos e geofísicos, nordeste do estado do Pará, Brasil, que possibilitou a elaboração deste artigo.

\section{REFERÊNCIAS}

ARAI, M. A grande elevação eustática do Mioceno: a verdadeira origem do Grupo Barreiras. Rio de Janeiro-RJ: Petrobras/CENPES/PDEXP/BPA, Ilha do Fundão, Cidade Universitária. 2006.

ARRANJO WENNER E ARRANJO SCHUMBERGER. Disp. em http://www.ebah.com.br/content/ABAAAga3kAE/ diagrafia-eletrica > acesso em: 20 de fevereiro de 2017.

FERREIRA, C.S. Características lito-paleontológicas na Formação Pirabas, estado do Pará. In: CONFERÊNCIA GEOLÓGICA DAS GUIANAS, 6, 1966, Belém. Anais... Belém: Departamento Nacional de Produção Mineral, 1966. v. 6, p. 101-111.

FREITAS FILHO, L.S.F. Prospecção de Água Subterrânea no Município de Novo Repartimento - PA Aplicando Métodos Elétricos e Eletromagnéticos. Belém, 2006. 49p. Dissertação (Mestrado), Universidade Federal do Pará.

GANDOLFO, O.C.B. Um estudo do imageamento geoelétrico na investigação rasa. São Paulo, 2007. Tese (Doutorado) - Instituto de Geociências, Universidade de São Paulo.

GÓES, A.M.; ROSSETTI, D.F.; NOGUEIRA, A.C.R.; TOLEDO, P.M. Modelo Deposicional Preliminar da Formação Pirabas no Nordeste do Estado do Pará. Boletim do Museu Paraense Emílio Goeldi. Série de Ciências do Terra, v. 2, 1990.

LOCAL DO LEVANTAMENTO NO MUNICÍPIO DE CAPANEMA. Disp. em < https://www.google.com.br/maps > acesso em: 20 de fevereiro de 2017.

LOCAL DO LEVANTAMENTO NO MUNICÍPIO DE PRIMAVERA. Disp. em < https://www.google.com.br/maps > acesso em: 20 de fevereiro de 2017.
ORELlANA, E. Prospeccion geoelectrica en corriente continua. Madrid: Paranifo, 1972. 523p.

PETRI, S. Foraminíferos Fósseis da Bacia do Marajó. Boletim da Faculdade de Filosofia, Ciências e Letras da Universidade de São Paulo. 172p. 1954

ROSSETI, D.F. Evolução Sedimentar miocenica nos estados do Pará e Maranhão. Revista do Instituto de Geociências-USP, São Paulo, v. 6, n. 2, p. 7-18, 2006.

ROSSETTI, D.F. \& GÓES, A.M. O Neógeno da Amazônia Oriental. Belém. Museu Paraense Emilio Goeldi, Coleção Friederich Katzer. 2004.

SILVA. F.S. Análise rasa de subsuperfície com radar de penetração no solo (GPR) em depósitos neógenos na praia da Atalaia (Salinas) e Aricuru (Maracanã), nordeste do estado do Pará. 2015. Belém, 42p. Monografia (Conclusão de Curso) - Faculdade de Geofísica, Instituto de Geociências, Universidade Federal do Pará.

SIAGAS, disp. em: < http://siagasweb.cprm.gov.br/layout/> acesso em: 20 de fevereiro de 2017.

VIEIRA, P.D.C. Estimativa do relevo 3d do embasamento via inversão gravimétrica da porção nordeste do Pará, município de Salinópolis e entorno, com separação regional-residual utilizando modelo gemma para profundidade da moho. 2015. 42p. Belém. Monografia (Conclusão de curso) - Faculdade de Geofísica, Instituto de Geociências, Universidade Federal do Pará.

Submetido em 10 de outubro de 2017 Aceito em 8 de fevereiro de 2018 